\title{
Evolution ventilator associated pneumonia (VAP) in our intensive care unit, after pneumonia zero (PZ) program implementation
}

\author{
R Fernández Fernández ${ }^{*}$ ME Yuste Ossorio, MR Ramírez Puerta, O Moreno Romero, M Muñoz Garach \\ From ESICM LIVES 2015 \\ Berlin, Germany. 3-7 October 2015
}

\begin{abstract}
Introduction
The National Survey of Nosocomial Infection Surveillance (ENVIN) is a computerized record of the incidence of nosocomial infection in ICU in Spain. Most international scientific societies have developed their own recommendations to avoid VAP. In our hospital, we have drafted rules for the maintenance of the airway in mechanically ventilated patients following general recommendations (PZ).
\end{abstract}

\section{Objectives}

We want to describe our program and the evolution of our rates after its implementation and compare it with Spanish data.

\section{Methods}

- Data from the ENVIN registration: 01.04.11/ 01.04.15. 682 hospital beds, 18 ICU beds.

- Conduct training and educational campaign (presencial and by means of internet) to professionals of ICU also including anesthesia-resuscitation unit (total of 112 people) with online assessment.

- Pharmacy Service prepared chlorhexidine (2\%) oral solution for oral cleaning, we asked for orotracheal tubes and tracheostomy cannulas subglottic suctioning, tubing and active humidification steam and created a hand hygiene group ...Were instituted mandatory measures for the prevention of VAP:proper training in airway management, strict hand hygiene, control of pneumopressure ball $\left(>20 \mathrm{cmH}_{2} \mathrm{O}\right)$, oral hygiene every 6-8 hours, avoid, whenever possible, supine position at $0^{\circ}$, reduce intubation and / or its

Hospital Universitario San Cecilio, Unidad Cuidados Intensivos, Granada Spain

c 2015 Fernández Fernández et al.; This is an Open Access article distributed under the terms of the Creative Commons Attribution License (http://creativecommons.org/licenses/by/4.0), which permits unrestricted use, distribution, and reproduction in any medium, provided the original work is properly cited. duration, prevent the programated change of tubing, humidifiers and tracheal tubes

- Statistical Support ENVIN: Rate/100 patients admitted, 100 patients mechanical ventilation (pMV), incidence density (ID)/1000 days of stay (ds), $1000 \mathrm{MV}$ days $(\mathrm{dMV}) . \mathrm{N}=4198$ pattients admitted, $805 \mathrm{pMV}$. 17575 ds, $6087 \mathrm{dMV}$

\section{Results}

01.04.11-01.04.12: 15 VAP. Rates: 1.46/admitted, 7.5/ pMV. ID: 3.1/ ds,8.73/dMV Germ: A. baumanii 44.44\%. Severe sepsis $33.33 \%$. Sepsis $33.33 \%$.

01.04.12-01.04.13: 6 VAP. Rates: 0.55/admitted, 3.03/ pMV. ID: $1.22 / \mathrm{ds}, 3.26 / \mathrm{dMV}$

Germ: S. aureus $22.22 \%$, S. maltophilia $22.22 \%$. Sepsis $50 \%$

01.04.13-01.04.14: 10 VAP. Rates: $0.89 /$ admitted, 4.65/pMV. ID: $2.04 / \mathrm{ds}, 6.11 / \mathrm{dMV}$

Germ: S. aureus $25 \%$, E. coli $16.67 \%$. Sepsis $50 \%$

01.04.14-01.04.15: 4 VAP. Rates: 0.42/admitted, 2.07/ pMV. ID: $0.95 / \mathrm{ds}, 2.71 / \mathrm{dMV}$

Germ: H.influenzae 25\%, K.oxytoca 25\%, P.aeuroginosa $25 \%$, S. liquefaciens $25 \%$.

Severe sepsis $50 \%$. Sepsis $50 \%$.

Spain last year: Rates: 2.48/admitted, 5.92/pMV. ID: $3.28 / \mathrm{ds}, 6.87 / \mathrm{dMV}$. Germ: P.aeuroginosa $21.1 \%$. Sepsis $56.4 \%$

\section{Conclusions}

Our PZ program, has very good results, we are below Spanish data and ENVIN target: " rate $<9 / 1000$ dMV" [1]. In 2013, we presented an increase in the rate of NAV in connection with lower adherence to recommendations. In the last year we have managed to reduce to less than half 
the number of NAV. This is due to increased monitoring of adherence to these recommendations. Sepsis is the most frecuent response. Germs vary each year.

\section{Grant Acknowledgment}

UCI H. S. Cecilio.

Published: 1 October 2015

\section{Reference}

1. [http://hws.vhebron.net/formacion-Nzero/Objetivos.html].

doi:10.1186/2197-425X-3-S1-A709

Cite this article as: Fernández Fernández et al:: Evolution ventilator associated pneumonia (VAP) in our intensive care unit, after pneumonia zero (PZ) program implementation. Intensive Care Medicine Experimental 2015 3(Suppl 1):A709.

\section{Submit your manuscript to a SpringerOpen ${ }^{\mathcal{O}}$ journal and benefit from:}

- Convenient online submission

- Rigorous peer review

- Immediate publication on acceptance

- Open access: articles freely available online

- High visibility within the field

- Retaining the copyright to your article 